\title{
Taurine Transport in the in Vitro Perfused Human Placenta
}

\author{
JUDITH U. HIBBARD, GABRIELLA PRIDJIAN, PETER F. WHITINGTON, AND \\ ATEF H. MOAWAD \\ Department of Obstetrics and Gynecology and Department of Pediatrics, University of Chicago, \\ Chicago, Illinois 60637
}

\begin{abstract}
Taurine, required by the fetus for nutrition and neurological development, is inadequately synthesized by the fetus and substantial quantities of the amino acid are supplied by the mother. Maternal to fetal unidirectional taurine transport was studied in in vitro perfused human placentae from normal term deliveries. To determine whether the placenta can achieve and maintain a chemical gradient for taurine, recirculating equimolar maternal and fetal perfusions were performed. The ratio of fetal/maternal taurine concentration increased over $75 \mathrm{~min}$ and was maintained at $1.38 \pm 0.14(\mathrm{SEM})$ through $2.25 \mathrm{~h}(n=6)$. To determine the rate of taurine transport against a concentration gradient, flux was determined with maternal taurine constant at $50 \mu \mathrm{M}$ whereas the fetal taurine concentration varied from 0 to $500 \mu \mathrm{M}$ in a nonrecirculating system $(n=5)$. Despite increasing the chemical gradient tenfold, taurine was transported at a constant rate of 1.75 $\pm 0.75(\mathrm{SEM}) \mathrm{nmol} / \mathrm{min} / \mathrm{g}$. Nonrecirculating perfusions were performed with $B$-alanine $(n=13)$ and hypotaurine $(n=10)$, both B-carrier competitors, and no inhibition of taurine transport could be detected, taurine flux being $104.1 \pm 6.0 \%(\mathrm{SEM})$ of baseline in the presence of $\mathrm{B}$ alanine and $106.0 \pm 7.0 \%(\mathrm{SEM})$ with hypotaurine. Finally, ouabain inhibited transport $(n=3)$ by $58.1 \pm 5.4 \%$ (SEM). We conclude that taurine is transported in the human placenta by an active carrier mechanism. (Pediatr Res 27: 80-84, 1990)
\end{abstract}

Abbreviation

AIB, $\alpha$-aminoisobutyric acid

Taurine, 2-aminoethanesulfonic acid, is a B-amino acid important for fetal and neonatal nutrition and neurologic development (1-4). It can be synthesized by mature liver and other tissues from methionine and cysteine and, therefore, is not an essential nutrient in adults. However, the human fetus and newborn have inadequate taurine synthesis to meet their needs (5). Therefore, there is a requirement for maternal-fetal transfer during pregnancy.

Taurine has been shown to be actively transported in several different tissues (Table 1 ) by the B-amino acid carrier or "B" carrier $(6,7)$. This carrier system has been described as a sodium-

Received August 29, 1988; accepted September 11, 1989.

Correspondence and reprint requests Judith U. Hibbard, M.D., Department of Obstetrics and Gynecology, The Chicago Lying-in Hospital, 5841 South Maryland Avenue, Chicago, IL 60637

Supported by the Mother's Aid Research Fund, Chicago Lying-in Hospital, the Cardiovascular Pathophysiology and Biochemistry Training Grant HL7237, and the American Diabetes Association Northern Illinois Young Investigator's Research Award dependent, saturable system (9-14) that is dependent on cellular respiration and temperature (15) as well as an external chloride gradient (16). The carrier is competitively inhibited by B-alanine and hypotaurine $(8-9,12,14-16)$. In some tissue taurine is transported by a dual mechanism of active transport at lower concentrations and diffusion at higher concentrations $(15,17-$ 19). The only human tissues in which taurine transport has been studied are platelets, lymphocytes, retina and, very recently, placental vesicles $(14,18-21)$. All transport taurine by a saturable, active carrier. Human platelets transfer taurine by both an active carrier mechanism and diffusion.

Little is known or understood about the mechanism by which taurine passes from the maternal to the fetal circulation. Sheep and guinea pig placenta seem not to transfer taurine $(22,23)$. However, Sturman and coworkers $(5,24)$ have demonstrated transfer of taurine in the rat and primate by injecting the mother with $\left[{ }^{35} \mathrm{~S}\right]$-taurine and recovering it in the fetal tissue. Stegink et al. (25) have demonstrated that primate placentae not only transfer taurine from the maternal to the fetal circulation, but also achieve and maintain a fetal/maternal taurine ratio of 1.351.50. No studies of taurine transfer in the intact human placenta have been performed other than measuring the concentration of taurine in the maternal serum and cord blood either at fetoscopy (26) (fetal/maternal taurine concentration ratio: 3.65) or at the time of delivery $(27,28)$ (fetal/maternal taurine concentration ratios: $3.14,2.25)$. However, taurine transport has been studied in placental brush-border membrane vesicles revealing an active carrier mechanism (21).

Most amino acids studied cross the placenta by an active transport mechanism $(22,29-32)$. A dual transfer phenomenon, one saturable and the other nonsaturable, has been demonstrated in human placental villous fragments, vesicles and slices (3335). In each of these three preparations AIB is transferred by active transport and diffusion. Uptake of alanine by human placental vesicles also exhibits two components (36). The model of Michaelis-Menton kinetics has been used to describe the saturable component of transport for AIB (33-35) and alanine (36) in human placental tissue and the active transport of proline in human placental vesicles (37). Three amino acid carrier systems have been described in the human placenta, the " $L$," "A," and "ASC" systems $(38,39)$. These carriers are similar to those described in other tissues with regard to the amino acids they transport and their overlapping substrate reactivities. A " $\mathrm{B}$ " carrier has been demonstrated in the human placenta in one study (21) using brush border vesicles. This study is designed to characterize the mechanism and rates of taurine transport by the human placenta in vitro.

\section{MATERIALS AND METHODS}

Placental perfusion. The technique of in vitro perfusion of a human placental cotyledon described by Schneider et al. (40) and Brandes et al. (41) was used with minor modification. Work 
TAURINE TRANSPORT IN PLACENTA

Table 1. Representative kinetic parameters for taurine transport

\begin{tabular}{|c|c|c|c|}
\hline Tissue & Species & $\mathrm{Km}(\mu \mathrm{M})$ & $\mathrm{V}_{\max }$ \\
\hline $\begin{array}{l}\text { Renal tubules ( } 8 \text { ) (brush border } \\
\text { vesicles) }\end{array}$ & Rat & 16.8 & $222.8 \mathrm{pmol} / \mathrm{mg}$ \\
\hline Brain synaptosomes (15) & Rat & $3.2-81$ & $3.0-33 \mathrm{nmol} / \mathrm{min} / \mathrm{g}$ prot \\
\hline $\begin{array}{l}\text { Intestine (9) (membrane vesicles, } \\
\text { everted jejunal sacs) }\end{array}$ & Rat & 25 & $24 \mathrm{pmol} / \mathrm{mg}$ prot $/ 10 \mathrm{~s}$ \\
\hline Retina (isolated) (17) & Cat & 47.8 & $0.55 \mathrm{nmol} / \mathrm{mg} / \mathrm{min}$ \\
\hline \multirow[t]{2}{*}{ (isolated) (13) } & Rat & 21 & $198 \mathrm{nmol} / \mathrm{g} / \mathrm{h}$ \\
\hline & & 312 & $2754 \mathrm{nmol} / \mathrm{g} / \mathrm{h}$ \\
\hline \multirow{2}{*}{ Sarcolemma $(10,11)$ (vesicles) } & Rat & 44.2 & $0.28 \mathrm{nmol} / \mathrm{mg} / \mathrm{min}$ \\
\hline & Guinea pig & 1.94 & $\begin{array}{l}0.18 \mathrm{pmol} / \mathrm{mg} \mathrm{prot} / \mathrm{min} \\
30 \mathrm{pmol} / \mathrm{mg} \mathrm{prot} / \mathrm{min}\end{array}$ \\
\hline \multirow{3}{*}{ Platelets $(18,19)$} & Human & $\begin{array}{l}15.0 \\
2.9-36\end{array}$ & $202 \mathrm{nmol} / \mathrm{min} / 10^{8}$ plat \\
\hline & 114uinate & $100-200$ & $59.1 \mathrm{nmol} / \mathrm{ml} \mathrm{plat} / \mathrm{min}$ \\
\hline & & 360 & \\
\hline Lymphoblastoid cells (14) & Human & 25 & $7.2 \mathrm{pmol} / \mathrm{min} / 10^{6}$ cells \\
\hline $\begin{array}{l}\text { Placenta (brush border vesicles) } \\
\text { (21) }\end{array}$ & Human & 6.5 & $27.7 \mathrm{pmol} / \mathrm{mg}$ prot $/ 15 \mathrm{~s}$ \\
\hline
\end{tabular}

from this laboratory has confirmed the viability of the model (42). To complete an experiment, a placenta is obtained immediately upon delivery, placed in iced Kreb's bicarbonate buffer and transported to the laboratory. The placenta is placed on an iced glass plate, and first degree ramifications of umbilical artery and vein are cannulated with polyvinylchloride tubing (Tygon, Norton, Akron, $\mathrm{OH}$ ) of appropriate diameter for perfusion of the fetal circuit. The placenta is then placed fetal-side down into a 9-cm diameter plexiglass perfusion chamber, consisting of two hemichambers that are separated by the placenta, maternal-side in the upper hemichamber and the fetal side in the lower. Maternal perfusion is accomplished by a circular polyvinylchloride manifold with two input and several polyethylene output cannulae that are pressed into the maternal syncytium. Maternal perfusate returns by pressure when the chamber is sealed.

The perfusate consists of Kreb's bicarbonate buffer, $4 \mathrm{~g} / \mathrm{dL}$ bovine serum albumin and $100 \mathrm{mg} / \mathrm{dL}$ of glucose. In experiments where perfusates are recirculated, washed packed red cells are added to a hematocrit of $10 \%$. This low hematocrit was chosen to minimize problems with thrombosis in the small vessels and capillaries, whereas providing adequate oxygenation for the tissue. In several experiments antipyrine and ${ }^{3} \mathrm{H}$-L-glucose were used as reference molecules. Antipyrine, a readily diffusable lipophillic substance, is added to the maternal perfusate at a concentration of $12 \mathrm{mg} / 100 \mathrm{~mL}$, a level at which no antipyrine metabolites are detected (43). Antipyrine concentrations in maternal and fetal perfusates are used to calculate clearance and an exchange index, which references the exchange of any compound in question to the clearance of antipyrine, for taurine. ${ }^{3} \mathrm{H}-\mathrm{L}-$ glucose, a molecule that diffuses across complex membranes via the paracellular pathway, was added to the maternal perfusate at a dose of $0.01 \mu \mathrm{Ci} / \mathrm{mL}$ in some experiments to assess membrane integrity. Perfusates are pumped by a peristaltic pump (Harvard Apparatus, Millis, MA) at a maternal rate of $12.0 \mathrm{~mL} / \mathrm{min}$ and a fetal rate of $4.2 \mathrm{~mL} / \mathrm{min}$. Flow rates are confirmed by timed collections. Oxygenation and equilibrium of $\mathrm{CO}_{2}$ content is accomplished by passing both perfusates through $50 \mathrm{~m}$ of thinwalled silastic tubing (0.058 inch inside diameter, Dow Corning, Midland, MI) enclosed in a glass vessel that is continuously gassed with humidified $95 \% \quad \mathrm{O}_{2}: 5 \% \mathrm{CO}_{2}$. Maternal and fetal arterial and venous $\mathrm{PO}_{2}$ are measured intermittently, and the arteriovenous gradient is in the range of 130-140 torr. Line perfusion pressures are monitored by a mercury manometer. The pressures in the intervillous space are generally less than $10 \mathrm{~mm}$ $\mathrm{Hg}$, whereas the fetal pressures range from $10-40 \mathrm{~mm} \mathrm{Hg}$. An infra-red radiant heater is used to rapidly warm the placenta to $38.0^{\circ} \mathrm{C}$, and perfusions are performed in a plexiglass cabinet that maintains the temperature at $38 \pm 1^{\circ} \mathrm{C}$ by a thermostatically controlled forced-air heating system. The $\mathrm{pH}$ of maternal and fetal perfusates are maintained in the range of 7.35-7.45 by dropwise additions of $1 \mathrm{~N} \mathrm{NaOH}$ or $1 \mathrm{~N} \mathrm{HCl}$. Afterward the portion of placenta being perfused is dissected free and dried to constant weight in a $43^{\circ} \mathrm{C}$ oven.

Substrate analysis. In all experiments ${ }^{14} \mathrm{C}$-[U]-taurine (Amersham Corp., Arlington Heights, IL) was used as tracer in the maternal perfusate at a concentration of $0.002 \mu \mathrm{Ci} / \mathrm{mL} .{ }^{3} \mathrm{H}-\mathrm{L}-$ glucose was obtained from New England Nuclear, Boston MA. One-mL aliquots of fetal perfusate were mixed with $10 \mathrm{~mL}$ of commercial scintillation fluid and radioactivity was measured in a Packard 2000 CA scintillation counter (Downers Grove, IL) with automatic external quench correction and spectral bioluminescence correction. The rate of maternal to fetal transfer was calculated by: $f=(\mathrm{dpm} / \mathrm{mL} \times \mathrm{FR} \times 1 / \mathrm{SA}) / \mathrm{g}$, where $f=$ flux rate for taurine in $\mu \mathrm{mol} / \mathrm{min} / \mathrm{g}, \mathrm{dpm} / \mathrm{mL}=$ disintegrations ${ }^{14} \mathrm{C} /$ $\mathrm{min} / \mathrm{mL}$ fetal perfusate, $\mathrm{FR}=$ flow rate of the fetal circuit in $\mathrm{mL} / \mathrm{min}, \mathrm{SA}=$ specific activity of taurine in the maternal perfusate in $\mathrm{dpm} / \mu \mathrm{mol}$, and $\mathrm{g}=$ dry wt of the perfused placenta in grams. Antipyrine was assayed using colorimetric methods (44). Clearance, exchange and exchange index were calculated according to the following formulas (32):

$$
\begin{aligned}
\text { clearance } & =\left([\text { antipyrine }]_{\mathrm{FV}} \times \mathrm{Q}_{\mathrm{F}}\right) /[\text { antipyrine }]_{\mathrm{MA}} \\
\text { exchange } & =\left(\mathrm{C}_{\mathrm{FV}} \times \mathrm{Q}_{\mathrm{F}}\right) / \mathrm{C}_{\mathrm{MA}} \\
\text { exchange index } & =\frac{\text { exchange of amino acid }}{\text { clearance of antipyrine }} \times 100
\end{aligned}
$$

where $C$ is the concentration of taurine in the fetal vein (FV) and the maternal artery (MA) and $\mathrm{Q}_{\mathrm{F}}$ is the fetal flow rate. Specific experimental conditions are given with the results. Results are expressed as mean $\pm \mathrm{SE}$ of the mean throughout. Student's $t$ test was used when appropriate.

Analysis of the radioactivity in the fetal perfusate from one experiment was performed on an ion exchange chromatographic column using a three step buffer gradient (Beckman 121-M Amino Acid Analyzer, Palo Alto, CA). The sample was split and one fraction subjected to postcolumn ninhydrin reaction to establish a retention time. Two fractions were run without the postcolumn reaction and the effluent sequentially collected and analyzed on the Packard $2000 \mathrm{CA}$ scintillation counter. This analysis revealed that the $\left[{ }^{14} \mathrm{C}\right]$ label was associated almost exclusively with taurine, indicating that the taurine was not metabolized as it was transported across the placenta. 


\section{RESULTS AND DISCUSSION}

Can perfused placenta create and maintain chemical gradient for taurine? A series of six experiments were performed to determine whether the perfused placenta could achieve and maintain a chemical gradient for taurine. The conditions of the experiments were as follows: the fetal and maternal effluent cannulae were returned to their respective perfusate reservoirs so the circuits were closed, i.e. recirculating. In three experiments the maternal and fetal perfusates were initially identical, containing $20 \mu \mathrm{M}$ taurine with ${ }^{14} \mathrm{C}$-taurine tracer. In the other three experiments antipyrine and ${ }^{3} \mathrm{H}$-L-glucose were added to the maternal perfusate. The recirculation perfusions were maintained for 2.25 h. One-mL samples were removed from the perfusate reservoirs every $15 \mathrm{~min}$ for analysis.

The ratio of fetal/maternal taurine concentration steadily increased during the first $75 \mathrm{~min}$ and then stabilized at $1.38 \pm 0.14$ through the remaining hour (Fig. 1). This gradient of 1.38 is similar to that achieved by Stegink et al. (25) in the primate placenta, which was $1.35-1.50$. Such a ratio suggests the presence of an active transport component for taurine from mother to fetus. Antipyrine begins to equilibrate in the system and reaches about $60 \%$ of the maternal concentration on the fetal side by the end of each experiment. L-Glucose, an inert reference substance, is transferred much more slowly than antipyrine, plateauing at less than $20 \%$ of the maternal concentration.

To determine whether taurine may be leaking from the fetal vessels into the saline beneath the fetal surface causing the measured ratio of 1.38 to be falsely low, ${ }^{14} \mathrm{C}$-taurine was measured in the saline at the end of four experiments. In all these, no significant taurine leakage was detected; specifically, in the recirculating experiment only $1.6 \%$ of the fetal perfusate ${ }^{14} \mathrm{C}$-taurine concentration was recovered in the saline.

What are taurine flux rates in presence of chemical gradient? An active carrier mechanism is able to transport substances against a chemical gradient. Five experiments were performed to determine the rate at which taurine is transported against an increasing fetal/maternal taurine concentration gradient by measuring unidirectional maternal to fetal taurine flux rates. In addition, exchange and exchange index were calculated for taurine for three experiments. In all the experiments the fetal and maternal effluents were collected and not returned to the perfusion reservoirs, so the circuits were open, i.e. nonrecirculating. The perfusates were identical except for the taurine concentra-

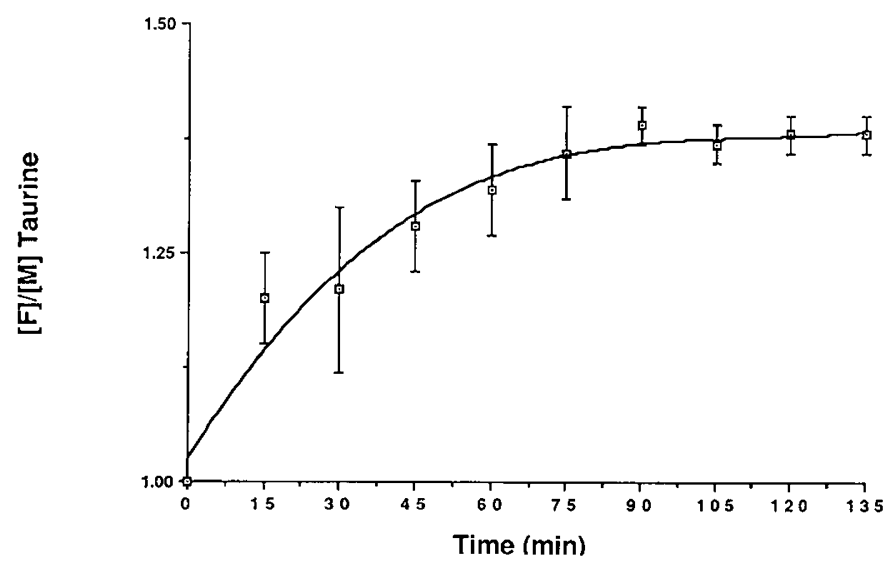

Fig. 1. Achievement of a fetal/maternal taurine concentration gradient. Initial equimolar maternal and fetal taurine concentrations change with time as perfusates are recirculated. Mean data points are shown from six perfusions. The ratio of fetal/maternal taurine concentration steadily increases over $75 \mathrm{~min}$ and is maintained at $1.38 \pm 0.14$ at 2.25 h $(r=0.98)$. The final gradient was calculated as the mean of the last five data points, between 75 to $135 \mathrm{~min}$, where the slope of the curve decreases significantly. tion, and the antipyrine added to the maternal perfusate in three experiments. ${ }^{14} \mathrm{C}$-taurine was added only to the maternal perfusate, and fetal effluent was collected in 4-min fractions to determine flux rates. The maternal taurine concentration was $50 \mu \mathrm{M}$ whereas eight fetal taurine concentrations $(0,10,25,50,75,100$, 200 , and $500 \mu \mathrm{M}$ ) were used. Each concentration was maintained for $30 \mathrm{~min}$. Because steady transport rates are achieved from 8 to $16 \mathrm{~min}$ after perfusate concentration changes, flux rates were determined from 16 to 30 min after changes were made. A mean flux rate, exchange, and exchange index were calculated for each fetal concentration and compared.

There was no difference among mean flux rates, exchange, or exchange indices. Final means were calculated using all data points. Despite increasing the fetal/maternal gradient 10 -fold, taurine was transported at a constant rate of $1.75 \pm 0.75 \mathrm{nmol} /$ $\mathrm{min} / \mathrm{g}$. The exchange, $0.502 \pm 0.035 \mathrm{~mL} / \mathrm{min}$, and exchange index, $49.1 \pm 7.4 \%$, for taurine also remained constant. When comparing this exchange index to values obtained for other amino acids (19-38\%) by Schneider et al. (32), it appears that taurine is an amino acid that is readily transported, higher than glutamine with an exchange index of $38.0 \%$, and higher than leucine at $36.0 \%$.

These experiments were designed to examine the net transfer of taurine due to diffusion in the maternal-fetal direction. As the fetal/maternal gradient increases, the likelihood of back diffusion from the fetus to the mother increases. Although diffusion from mother to fetus can still occur at high $[\mathrm{F}] /[\mathrm{M}]$ gradients, this would be small under these conditions. If the transfer of taurine were the result of diffusion, the maternal-fetal flux would decline as the fetal-maternal gradient is raised. However, flux remains constant at $1.75 \pm 0.75 \mathrm{nmol} / \mathrm{min} / \mathrm{g}$. Thus, these data suggest that most of the taurine transfer at a maternal concentration of $50 \mu \mathrm{M}$, which is near the $\mathrm{Km}$ for transport by other tissues, is probably the result of active transport.

Do B-carrier competitors inhibit taurine transport and does ouabain? Inhibition of taurine transport was tested in a total of 23 placentae. The experimental conditions were the same as in the preceding five experiments.

B-alanine, a B-amino acid analogue of taurine, was investigated as a competitive inhibitor of taurine. B-alanine concentration ranged from 1- to 1000 -fold over the concentration of taurine $(n=13)$. Equimolar maternal and fetal taurine concentrations were held constant at 50,100 , or $150 \mu \mathrm{M}$. Flux was determined before and 16-45 min after the addition of B-alanine to the perfusate. No inhibition of taurine transport was apparent. The taurine flux was $104.1 \pm 6.0 \%$ of baseline in the presence of B-alanine.

Hypotaurine, a structural analog of taurine, was tested $(n=$ 10) at concentrations ranging from 10 - to 300 -fold over the constant equimolar maternal and fetal taurine concentration of $10 \mu \mathrm{M}$. Again, there was no inhibition of taurine transport with taurine flux $106.0 \pm 7.0 \%$ of baseline without hypotaurine present.

In contrast to the B-amino carrier described in other tissues $(8,9,12,14-16)$ and in placental vesicles $(21)$, B-alanine and hypotaurine did not inhibit taurine transport in these experiments. It is possible that the concentrations of inhibitors used were not sufficiently high to inhibit taurine transport. Kudo et al. (45) used inhibitory concentrations 1500 times that of the amino acid under investigation in amino acid inhibition experiments using microvillous membrane vesicles. We may not have seen inhibition because there are a multiplicity of transport systems for taurine in the placenta, or the carrier for taurine transfer in the in vitro placenta may be specific. We conclude from these studies that taurine transport by the in vitro placenta does not show competitive inhibition by B-alanine and hypotaurine under the conditions of these experiments. To attempt resolution of these conflicting results, repetition of the work by Miyamoto et al. (21) is currently in progress. 
Ouabain, an inhibitor of sodium-potassium ATPase, was studied in nonrecirculating experiments $(n=3)$ with $100 \mu \mathrm{M}$ maternal and fetal taurine and 250-500 $\mu \mathrm{M}$ ouabain. Inhibition of taurine transport was seen after 8-12 min, with flux being reduced by $58.1 \pm 5.4 \%$ of the baseline, which is similar to the ouabain inhibition of taurine transport in lymphoblastoid cells (40-50\% decrease) (14). These results suggest that the active taurine carrier is sodium-potassium ATPase dependent. However, sodium-potassium ATPase is important for maintenance of so many cellular functions that the ouabain effect on taurine transport could be an indirect one. However, it does suggest that about one half of flux at $100 \mu \mathrm{M}$ maternal taurine is not due to simple diffusion.

Model of taurine transport by in vitro placenta. The human hemochorial placenta is a complex membrane that presents several barriers between the maternal circulation and that of the fetus. These include the maternal-facing brush border membrane of the syncytiotrophoblast and the basal membrane of the syncytium. The fetal capillary endothelial cell presents two additional membrane barriers through which substances must pass before entering the fetal blood. The active transport process may take place in any of these membranes, and the location of the active transport mechanism(s) could have a major effect on the overall process of maternal-to-fetal taurine transfer. For example, active transport occurring at the brush border or the basolateral membrane of the syncytium could drive taurine diffusion across the fetal capillary endothelium. As long as the fetal endothelial intracellular concentration is greater than the concentration in the fetal perfusate, taurine could pass the final membrane barrier by diffusion down a concentration gradient. Total placental tissue taurine concentrations have been measured and are quite high (3.5 $\mu \mathrm{M} / \mathrm{g}$ wet wt) (26). Taurine concentrations have not been measured in fetal capillary endothelial cells, making this theory difficult to prove. Work with microvillous membrane vesicles $(21,35-37,45,46)$ suggests that active transport carriers exist in the first maternal facing membrane, i.e., the microvillous membrane. Also, sodium-potassium ATPase is found in high concentration in the basal cell membrane of the human trophoblast and this membrane is likely to be the site of additional transport carriers (47). Little is known about specific transport across the fetal capillary membranes.

The in vitro human perfused placenta model, because of its similarity to the in situ human organ, can be used to study net fluxes from the mother to the fetus under simulated physiologic conditions. Total flux across the placenta is the sum of molecular movement across at least four membrane barriers. The model of the perfused human placenta is limited because it cannot provide specific information regarding each individual membrane. We hypothesize that both active transport and diffusion components for taurine transport exist in the human placenta. Our inability to detect inhibition of taurine transport by B-alanine and hypotaurine may be related to the complexity of the model or to its inherent limitations. Membrane isolation techniques must be used to characterize each membrane with regard to transport to fully understand the process.

\section{CONCLUSION}

Taurine is transferred from the maternal to the fetal circulation in the in vitro perfused placenta by active transport. The perfused human placenta is able to achieve and maintain a chemical gradient for taurine, and to transport against an increasing fetal/ maternal taurine concentration gradient. Our results indicate an active carrier system in the placenta similar to that found in other animal and human tissues. However, B-alanine and hypotaurine do not competitively inhibit active taurine transport in this model in contrast to the B-amino carrier as described in other tissues and in placental vesicles. Finally, ouabain inhibits the transport of taurine, implying that the active taurine carrier is sodium-potassium ATPase dependent. The full characterization of the taurine carrier in the placenta requires further investigation.

Acknowledgments. The authors express their gratitude to Mark C. Hibbard for his assistance in the computer analysis of the data and to Giri Reddy for his assistance in the amino acid analysis for taurine.

\section{REFERENCES}

1. Sturman JA, Moretz RC, French JH, Wisniewske HM 1985 Taurine deficiency in the developing cat: persistence of the cerebellar external granule cell layer. In: Oja SS, Ahtee L, Kontro P, Paasonen MK (eds) Taurine: Biological Actions and Clinical Perspectives. Alan R Liss Inc., New York, pp 43-52

2. Hayes KC, Carey RE, Schmidt SY 1975 Retinal degeneration associated with taurine deficiency in the cat. Science 188:949-951

3. Geggel HS, Ament ME, Heckenlively JR, Martin DA, Kopple JD 1985 Nutritional requirement for taurine in patients receiving long-term parenteral nutrition. N Engl J Med 312:142-146

4. Raiha NB, Rassin P, Heinonen K, Gaull G 1975 Milk protein quantity and quality: biochemical and growth effects in low birth weight infants. Pediatr Res 9:370(abstr)

5. Sturman JA, Hayes KC 1980 Biology of taurine in nutrition and development. Adv Nutr Res 3:231-299

6. Chesney RW, Scriver CR, Mohyuddin F 1976 Localization of the membrane defect in transepithelial transport of taurine by parallel studies in vivo and in vitro in hypertaurinuric mice. J Clin Invest 57:183-193

7. Dantzler WH, Silbernagel S 1976 Renal tubular reabsorption of taurine, $\gamma$ aminobutyric acid (GABA) and B-alanine studied by continuous microperfusion. Pfluegers Arch 367:123-128

8. Rozen R, Tenenhouse S, Scriver CR 1979 Taurine transport in renal brush border membrane vesicles. Biochem J 180:245-248

9. Barnard JA, Thaxter S, Kikuchi K, Ghishan FK 1988 Taurine transport by rat intestine. Am J Physiol 254:G334-G338

10. Franconi F, Martini F, Manghi A, Galli A, Bennardini F, Giotti A 1981 Uptake of $\left[{ }^{3} \mathrm{H}\right]$ taurine into myocardial membranes. Biochem Pharmacol 30:77-80

11. Franconi F, Martini F, Bennardini F, Mangiapane A, Giotti A 1981 Taurine uptake in sarcolemma vesicles isolated from hypertrophic guinea-pig hearts. Biochem Pharmacol 30:693-695

12. Hardison WGM, Weiner R 1980 Taurine transport by rat hepatocytes in primary culture. Biochim Biophys Acta 598:145-152

13. Scaleda, R 1980 High-affinity taurine uptake in developing retina. Neurochem Res 5:561-572

14. Tallan HH, Jacobson E, Wright CE, Schneidman K, Gaull GE 1983 Taurine uptake by cultured human lymphoblastoid cells. Life Sci 33:1853-1860

15. Meiners BA, Speth RC, Bresolin N, Huxtable R, Yamamura HI 1980 Sodiumdependent, high-affinity taurine transport into rat brain synaptosomes. Fed Proc 39:2695-2700

16. Chesney RW, Gusowski N, Dabbagh S, Theissen M, Padilla M, Diehl A 1985 Factors affecting the transport of B-amino acids in rat renal brush-border membrane vesicles. The role of external chloride. Biochim Biophys Acta $812 ; 702-712$

17. Schmidt SY 1980 High-affinity uptake of $\left[{ }^{3} \mathrm{H}\right]$ taurine in isolated cat retinas: effects of $\mathrm{Na}^{+}$and $\mathrm{K}^{+}$. Exp Eye Res 31:373-379

18. Wright CE, Tallan HH, Lin YY 1986 Taurine: biological update. Annu Rev Biochem 55:427-453

19. Ahtee L, Boullin DJ, Paasonen MK 1974 Transport of taurine by normal human blood platelets. Br J Pharmacol 52:245-251

20. Schmidt SY, Berson EL 1980 Postmortem metabolic capacity of photoreceptor cells in human and rat retinas. Invest Ophthalmol Vis Sci 19:1274-1280

21. Miyamoto Y, Balkovetz DF, Leibach FH, Mahesh VB, Ganapathy V 1988 $\mathrm{Na}^{+}+\mathrm{Cl}^{-}$-gradient-driven, high-affinity, uphill transport of taurine in human placental brush-border membrane vesicles. FEBS Lett 231:263-267

22. Lemons JA, Adcock EW, Jones MD, Naughton MA, Meschia G, Battaglia FC 1976 Umbilical uptake of amino acids in the unstressed fetal lamb. J Clin Inv 58:1428-1434

23. Eaton BM, Yudilevich DL 1981 Uptake and asymmetric efflux of amino acids at maternal and fetal sides of placenta. Am J Physiol 241:C106-C112

24. Sturman JA, Rassin DK, Gaull GE 1977 Taurine in developing rat brain: maternal-fetal transfer of $\left.{ }^{35} \mathrm{~S}\right]$ taurine and its fate in the neonate. $J$ Neurochem 28:31-39

25. Stegink LD, Reynolds WA, Pitkin RM, Cruikshank DP 1981 Placental transfer of taurine in the rhesus monkey. Am J Clin Nutr 24:2685-2692

26. Soltesz G, Harris D, Mackenzie IZ, Aynsley-Green A 1985 Metabolic and endocrine milieu of the human fetus and mother at 18-21 weeks of gestation. I. Plasma amino acid concentrations. Pediatr Res 19:91-93

27. Young M, Prenton MA 1969 Maternal and fetal plasma amino acid concentrations during gestation and in retarded fetal growth. J Obstet Gynaecol $\mathrm{Br}$ Cwlth 76:333-344

28. Phillips AF, Holzman IR, Teng C, Battaglia FC 1978 Tissue concentrations of free amino acids in term human placentas. Am J Obstet Gynecol 131:881887

29. Yudilevich DL, Sweiry JH 1985 Transport of amino acids in the placenta Biochim Biophys Acta 822:169-201 
30. Hill PMM, Young M 1973 Net placental transfer of free amino acids against varying concentrations. J Physiol 235:409-422

31. Miller RK, Berndt WO 1974 Characterization of neutral amino acid accumulation by human term placental slices. Am J Physiol 227:1236-1242

32. Schneider H, Mohlen KH, Dancis J 1979 Transfer of amino acids across the in vitro perfused human placenta. Pediatr Res 13:236-240

33. Miller RK, Berndt WO 1974 Characterization of neutral amino acid accumulation by human term placental slices. Am J Physiol 227:1236-1242

34. Smith CH, Adcock EW, Teasdale F, Meschia G, Battaglia FC 1973 Placental amino acid uptake: tissue preparation, kinetics, and preincubation effect. Am J Physiol 224:558-564

35. Ruzycki SM, Kelley LK, Smith CH 1978 Placental amino acid uptake. IV. transport by microvillous membrane vesicles. Am J Physiol 234:C27-C35

36. Assai M, Keino H, Kashewanata S 1982 L-Alanine uptake by microvillous brush border membrane vesicles prepared from human placenta. Biochem Int 4:377-384

37. Boyd CAR, Lund EK 1981 L-Proline transport by brush border membrane vesicles prepared from human placenta. J Physiol 315:9-19

38. Enders RH, Judd RM, Donohue TM, Smith CH 1976 Placental amino acid uptake. III. transport systems for neutral amino acids. Am J Physiol 230:706710

39. Steel RB, Smith CH, Kelley LK 1982 Placental amino acid uptake. VI.
Regulation by intracellular substrate. Am J Physiol 243:C46-C51

40. Schneider H, Panigel M, Dancis J 1972 Transfer across the perfused human placenta of antipyrine, sodium, and leucine. Am J Obstet Gynecol 114:822828

41. Brandes JM, Tavoloni N, Potter BJ, Sarkozi L, Shepard MD, Berk PD 1983 A new recycling technique for human placental cotyledon perfusion: application to studies of the fetomaternal transfer of glucose, inulin, and antipyrine. Am J Obstet Gynecol 146:800-806

42. Black DD, King K, Whitington PF 1984 Metabolism of very low density lipoprotein (VLDL) by human placenta in vitro. Pediatr Res 18:355(abstr)

43. Schenker S, Dicke J, Johnson RF, Mor LL, Henderson GI 1987 Human placental transport of cimetidine. J Clin Invest 80:1428-1434

44. Brodie BB, Axelrod J, Soberman R, Levy B 1949 The estimation of antipyrine in biological materials. J Biol Chem 179:25-29

45. Kudo X, Yamada K, Fujiwara A, Kawasaki T 1987 Characterization of amino acid transport systems in human placental brush-border membrane vesicles. Biochim Biophys Acta 904:309-318

46. Johnson LW, Smith CH 1988 Neutral amino acid transport systems of microvillous membrane of human placenta. Am J Physiol 254:C773-C780

47. Kelley LK, Smith CH, King BF 1983 Isolation and partial characterization of the basal cell membrane of human placental trophoblast. Biochim Biophys Acta 734:91-98 